\title{
Boiling Experiment Facility for Heat Transfer Studies in Microgravity
}

Richard DeLombard, John McQuillen, and David Chao

Glenn Research Center, Cleveland, Ohio 


\section{NASA STI Program . . . in Profile}

Since its founding, NASA has been dedicated to the advancement of aeronautics and space science. The NASA Scientific and Technical Information (STI) program plays a key part in helping NASA maintain this important role.

The NASA STI Program operates under the auspices of the Agency Chief Information Officer. It collects, organizes, provides for archiving, and disseminates NASA's STI. The NASA STI program provides access to the NASA Aeronautics and Space Database and its public interface, the NASA Technical Reports Server, thus providing one of the largest collections of aeronautical and space science STI in the world. Results are published in both non-NASA channels and by NASA in the NASA STI Report Series, which includes the following report types:

- TECHNICAL PUBLICATION. Reports of completed research or a major significant phase of research that present the results of NASA programs and include extensive data or theoretical analysis. Includes compilations of significant scientific and technical data and information deemed to be of continuing reference value. NASA counterpart of peer-reviewed formal professional papers but has less stringent limitations on manuscript length and extent of graphic presentations.

- TECHNICAL MEMORANDUM. Scientific and technical findings that are preliminary or of specialized interest, e.g., quick release reports, working papers, and bibliographies that contain minimal annotation. Does not contain extensive analysis.

- CONTRACTOR REPORT. Scientific and technical findings by NASA-sponsored contractors and grantees.

- CONFERENCE PUBLICATION. Collected papers from scientific and technical conferences, symposia, seminars, or other meetings sponsored or cosponsored by NASA.

- SPECIAL PUBLICATION. Scientific, technical, or historical information from NASA programs, projects, and missions, often concerned with subjects having substantial public interest.

- TECHNICAL TRANSLATION. Englishlanguage translations of foreign scientific and technical material pertinent to NASA's mission.

Specialized services also include creating custom thesauri, building customized databases, organizing and publishing research results.

For more information about the NASA STI program, see the following:

- Access the NASA STI program home page at http://www.sti.nasa.gov

- E-mail your question via the Internet to help@ sti.nasa.gov

- Fax your question to the NASA STI Help Desk at 301-621-0134

- Telephone the NASA STI Help Desk at 301-621-0390

- Write to: NASA Center for AeroSpace Information (CASI) 7115 Standard Drive Hanover, MD 21076-1320 
NASA/TM-2008-215148

AIAA-2008-0814

\section{Boiling Experiment Facility for Heat Transfer Studies in Microgravity}

Richard DeLombard, John McQuillen, and David Chao

Glenn Research Center, Cleveland, Ohio

Prepared for the

46th Aerospace Sciences Meeting and Exhibit

sponsored by the American Institute of Aeronautics and Astronautics

Reno, Nevada, January 7-10, 2008

National Aeronautics and

Space Administration

Glenn Research Center

Cleveland, Ohio 44135 
Trade names and trademarks are used in this report for identification only. Their usage does not constitute an official endorsement, either expressed or implied, by the National Aeronautics and Space Administration.

Level of Review: This material has been technically reviewed by technical management.

Available from

NASA Center for Aerospace Information 7115 Standard Drive

Hanover, MD 21076-1320
National Technical Information Service 5285 Port Royal Road Springfield, VA 22161

Available electronically at http://gltrs.grc.nasa.gov 


\title{
Boiling Experiment Facility for Heat Transfer Studies in Microgravity
}

\author{
Richard DeLombard, John McQuillen, and David Chao \\ National Aeronautics and Space Administration \\ Glenn Research Center \\ Cleveland, Ohio 44135
}

\begin{abstract}
Pool boiling in microgravity is an area of both scientific and practical interest. By conducting tests in microgravity, it is possible to assess the effect of buoyancy on the overall boiling process and assess the relative magnitude of effects with regards to other "forces" and phenomena such as Marangoni forces, liquid momentum forces, and microlayer evaporation. The Boiling eXperiment Facility is now being built for the Microgravity Science Glovebox that will use normal perfluorohexane as a test fluid to extend the range of test conditions to include longer test durations and less liquid subcooling. Two experiments, the Microheater Array Boiling Experiment and the Nucleate Pool Boiling eXperiment will use the Boiling eXperiment Facility. The objectives of these studies are to determine the differences in local boiling heat transfer mechanisms in microgravity and normal gravity from nucleate boiling, through critical heat flux and into the transition boiling regime and to examine the bubble nucleation, growth, departure and coalescence processes. Custom-designed heaters will be utilized to achieve these objectives.
\end{abstract}

\section{Nomenclature}

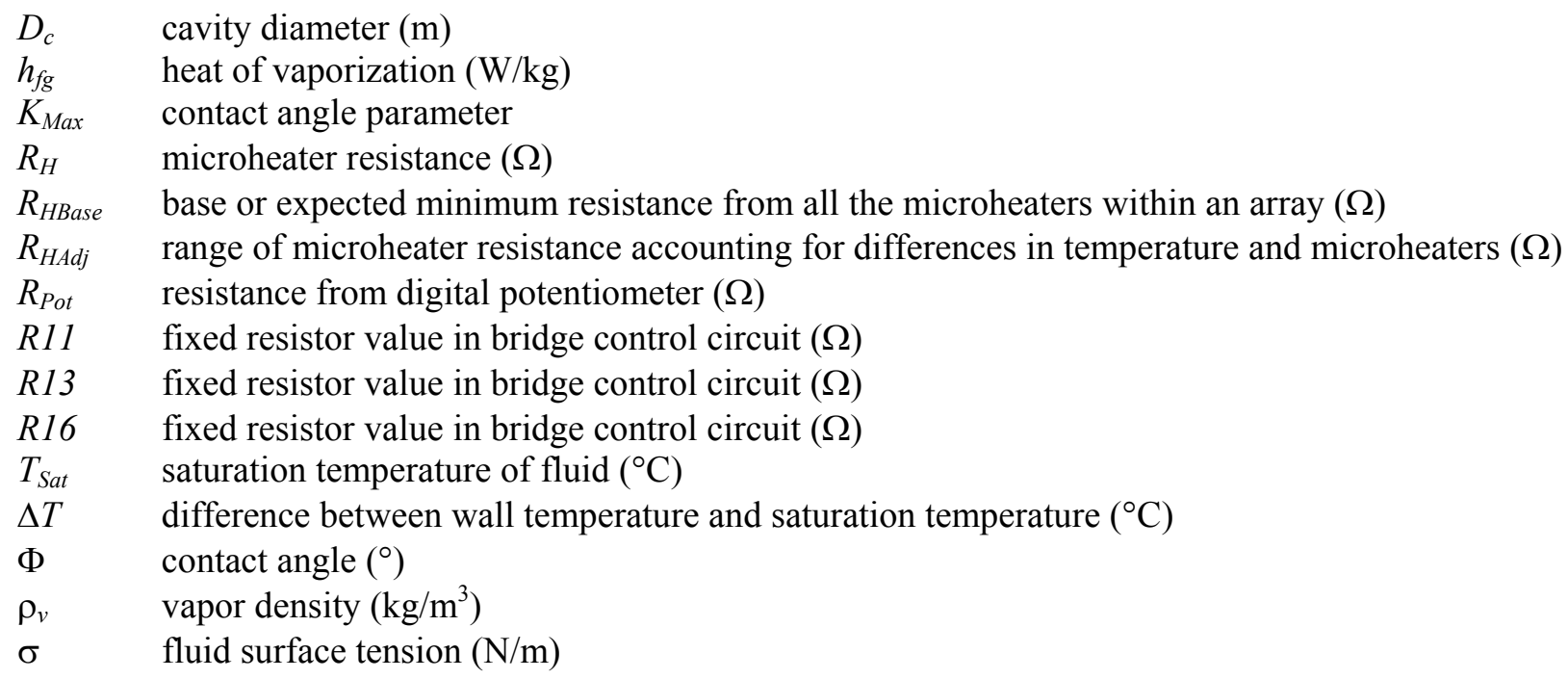

\section{Acronyms}

$\begin{array}{ll}\text { AB } & \text { Avionics Box } \\ \text { BXF } & \text { Boiling Experiment Facility } \\ \text { CHF } & \text { critical heat flux } \\ \text { COTS } & \text { Commercial Off-The-Shelf } \\ \text { CV } & \text { Containment Vessel } \\ \text { EC } & \text { embedded controller } \\ \text { EDM } & \text { electrical discharge machining }\end{array}$




$\begin{array}{ll}\text { GB } & \text { gigabytes } \\ \text { GRC } & \text { Glenn Research Center } \\ \text { ISS } & \text { International Space Station } \\ \text { MABE } & \text { Microheater Array Boiling Experiment } \\ \text { MLC } & \text { MSG Laptop Computer } \\ \text { MSDS } & \text { Material Safety Data Sheet } \\ \text { MSG } & \text { Microgravity Science Glovebox } \\ \text { NPBX } & \text { Nucleate Pool Boiling Experiment } \\ \text { nPFH } & \text { normal-perfluorohexane } \\ \text { PBE } & \text { Pool Boiling Experiment } \\ \text { PFiB } & \text { perfluoroisobutene } \\ \text { PGA } & \text { pin grid assembly } \\ \text { SAMS } & \text { Space Acceleration Measurement System } \\ \text { SPLC } & \text { ISS rack controller } \\ \text { TCCS } & \text { Trace Contaminant Control Subassembly } \\ \text { TSC } & \text { Telescience Support Center }\end{array}$

\section{Introduction}

Boiling is a complex phase transition process where the physics of hydrodynamics, heat transfer, mass transfer, and interfacial phenomena are tightly interwoven and affected by both the magnitude and direction of the gravity (acceleration) vector. Space system designers in their quest to build less massive and more efficient hardware such as heat exchangers, cryogenic fuel storage systems, and thermal management systems are always searching for techniques to transfer large amounts of heat with relatively little increase in the temperature of the heat transfer fluid.

While "flow boiling" is the principal fundamental problem with most of these systems, "pool boiling" has been studied to a greater extent for a variety of reasons including size and power constraints available to the experimenter. Nonetheless, pool boiling remains of intense interest for multiple reasons. First, some approaches to predicting the flow boiling heat transfer coefficient utilize a function that combines both the pool boiling heat transfer coefficient with a single-phase liquid convection heat transfer coefficient. Though this technique is not even remotely accurate, it does suggest that it may be possible to achieve flows that are dominated by inertia and hence gravity-independent at flow velocities greater than $1.5 \mathrm{~m} / \mathrm{s}$ (ref. 1). In addition, pool boiling can be viewed as a limiting case of flow boiling whereby the flow is stopped, either intentionally or accidentally. In these cases, there is usually some remaining thermal inertia that must be dissipated. Finally, pool boiling is directly applicable to cases involving the storage tanks of volatile liquids, such as cryogens, that are subjected to heat leaks into the tank.

As such, the influence of gravity (normal, lunar, Martian, and microgravity) and similar effects from mechanical forces (such as vibration, atmospheric drag) are important towards developing an understanding of boiling heat transfer and critical heat flux for space-based applications.

Perhaps the first boiling experiment conducted in microgravity was by Siegel and Keshock in a small $1.2 \mathrm{sec}$ drop tower (ref. 2). Over time, the nature of these studies has varied to examine pool boiling from a wire, a flat plate and a sphere. Test fluids have included water, water and ethanol, pentane and refrigerants such as R-113. Experiments have been conducted in drop towers, aircraft flying parabolic trajectories, sounding rockets and the space shuttle such as the Pool Boiling Experiment (PBE). The Pool Boiling Experiment conducted boiling studies on STS-47, -57, -60,-72, and -77, and found that steady state pool boiling was possible in microgravity under certain conditions; the heat transfer was enhanced due to small bubbles migrating toward a larger one because of temperature dependent surface tension effects; the pool boiling curve indicated an enhancement in the nucleate boiling regime, which increases with subcooling as compared to boiling on earth; and the high heater surface temperatures at the onset of boiling resulted in the explosive growth of vapor bubbles, also under certain conditions (ref. 3). 
Dimarco (ref. 4), Kim (ref. 5), and Ohta (ref. 6) provide a review of pre-2003 experiments. Work is still ongoing including recent publications by $\mathrm{Wu}$, Dhir and Qian (ref. 7), and Raj and Kim (ref. 8) among others.

The Boiling Experiment Facility (BXF) is part of the International Space Station (ISS) Research Project which uses the ISS as a microgravity research platform. The object of the BXF project is to study boiling heat transfer mechanisms in microgravity by incorporating two experiments in a single apparatus. Professor Jungho Kim of the University of Maryland, is the principal investigator for the Microheater Array Boiling Experiment (MABE). This experiment uses two constant temperature microheater arrays to develop the relationships between local phase distribution and heat transfer correlation. Professor Vijay K. Dhir of the University of California, Los Angeles, is the principal investigator for the Nucleate Pool Boiling Experiment (NPBX). This experiment uses an aluminum wafer with discrete boiling nucleation sites in order to develop and verify bubble growth, coalescence and departure models for boiling heat transfer.

\section{Boiling Experiment Facility}

The BXF flight apparatus is depicted in figure 1 and is comprised of two major components that will be mounted inside the ISS Microgravity Science Glovebox (MSG); a Containment Vessel (CV) and an Avionics Box (AB). In addition, local acceleration measurements will be provided by a Space Acceleration Measurement System (SAMS) head mounted within the MSG. The CV is comprised of a boiling chamber, a fluid control system, a temperature control system, a pressure control system, electronic and video data sensors, and heater control circuitry. A Commercial Off-The-Shelf (COTS) high-speed digital imager and microscopic lens is affixed to the CV to peer through several windows into the boiling chamber. The primary functions of the Avionics Box are power conversion and distribution and computer control for the facility operation. The signal processing electronics for the high-speed digital imager is attached to the top of the AB. More detail is provided below.

\section{Containment Vessel}

As was mentioned earlier, the $\mathrm{CV}$ encompasses the boiling chamber and everything related to conditioning the fluid for the experiment. In addition, NTSC cameras and embedded control boards are also incorporated within the structure. This design was necessitated since the Microgravity Science Glovebox is unable to provide three levels of containment for fluid quantities exceeding $100 \mathrm{ml}$. The BXF has approximately 4 liters of test fluid total.

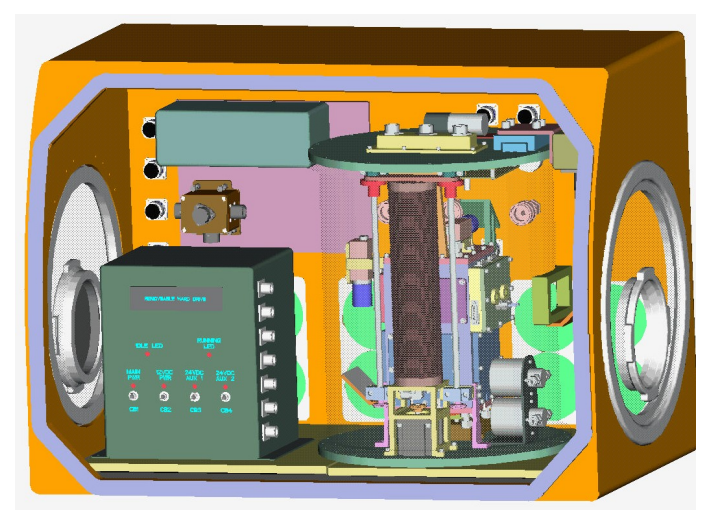

Figure 1.-BXF mounted in MSG with "transparent" CV. 


\section{Test fluid}

The test fluid is normal-perfluorohexane (nPFH), which is the linear isomer of $\mathrm{C}_{6} \mathrm{~F}_{14}$. This isomer is also the principal constituent of FC-72, a heat transfer fluid manufactured by $3 \mathrm{M}$. The nPFH was selected as the test fluid to address a safety concern raised by a NASA toxicologist and concerns that the other isomers within FC-72 could generate perfluoroisobutene (PFiB), a toxin that is classified as a Class II Weapons of Mass Destruction and has an acceptable exposure limit of 10 parts per billion or less, when exposed to temperatures above $200^{\circ} \mathrm{C}$. The safety concern was based on a caution statement within the Material Safety Data Sheet and because of the chemical similarity of a FC-72 isomer to some of the branched isomers studied by Tortelli and Tonelli (ref. 9).

While the BXF has safety shutdowns to limit the temperatures within the boiling chamber to no more than $60{ }^{\circ} \mathrm{C}$, if there were a leak, the ISS Trace Contaminant Control Subassembly (TCCS), has a catalytic reactor bed that operates in excess of $450^{\circ} \mathrm{C}$. Based on an extensive literature review and a series of experiments under exposure conditions similar to the ISS TCCS, these concerns were alleviated (ref. 10). However, because of the chemical composition of FC-72 and the difference in the normal boiling temperatures of some of the constituents (ref. 11), the test fluid was changed to nPFH.

\section{Boiling chamber}

The boiling chamber is fabricated from aluminum and its interior dimensions are approximately 228 by 114 by $114 \mathrm{~mm}$. An external view of the chamber is shown in figure 2 . A cutaway, top-down view is shown in figure 3 that shows the placement of the NPBX heater wafer on the bottom of the chamber and the two MABE microheater arrays on the side.

There are multiple windows to visualize both of the side view images of the NPBX wafer and the side view of the MABE microheater arrays. NTSC video cameras capture each of these side views for recording to the MSG video tape recorders. These cameras are mounted to the boiling chamber. Because the microheater arrays are semi-transparent, it is possible to view through the microheater array and a back-side cooling chamber. The cooling chamber will be discussed in greater detail later. This view through the bottom of the MABE microheater array is captured at 500 images per second for $4 \mathrm{sec}$ per test using a Photron Ultima- 512 high speed digital imager with 512 by 512 pixel resolution. Image data captured by this camera is stored for post-flight data analysis on removable hard drives. LED's are used to provide backlighting for each of the views.

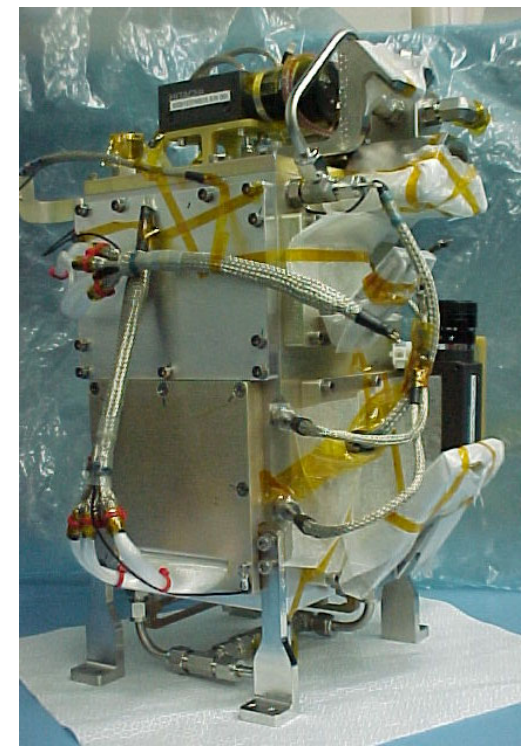

Figure 2.-BXF boiling chamber during fabrication and assembly.

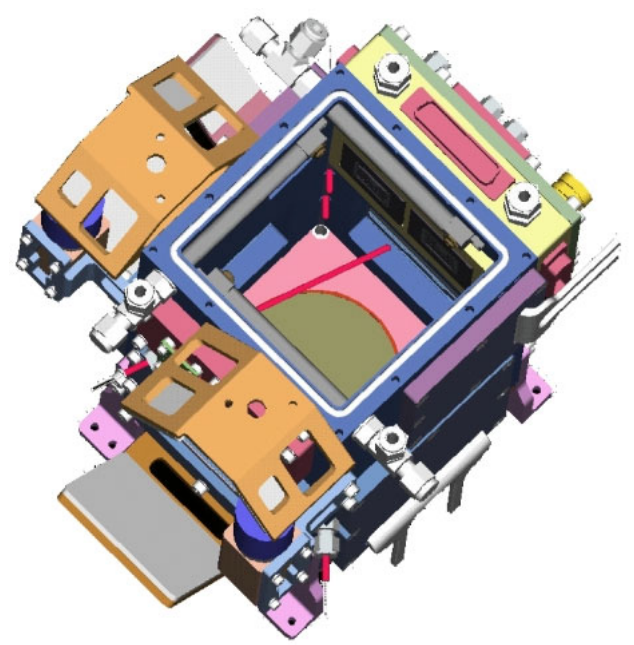

Figure 3.-Cutaway view of boiling hamber. 


\section{Flow system}

The flow system has been designed to condition the test fluid, maintain system pressure during a test, and provide cooling to the backside of the MABE microheater arrays. The flow path is illustrated in figure 4 and includes parallel pumps, isolation solenoid valves, filter, flow meter, check valves, heat exchanger, cooling chamber, heaters and the boiling chamber.

To mitigate the risk associated with part failure, redundancy is provided in both the pumps and the solenoid valves. Only one valve and pump will be operated at any given time. The pumps are gear pumps and were run for approximately $100 \mathrm{hr}$ to minimize the amount of impellor material that is shed into the flow. This protocol was based on the pump manufacturer's recommendation. Nonetheless, a $10 \mu \mathrm{m}$ filter is placed downstream of the pumps to capture any debris that may get shed into the flow.

The solenoid valves are "normally-open," i.e., in an unpowered state, the spring forces the valve stem to the open position. Thus, for most failure modes, the valve is open. The valves are commanded to the shut position to isolate the boiling chamber from flow. However, only one valve is shut at any time to allow both the fluid in the boiling chamber and in the cooling chamber to expand and contract in order to maintain system pressure.

Flow into the boiling chamber is through three tubes at the top of the chamber. These tubes surround cartridge heaters which are used to condition the fluid. Six thermisters are used to measure the fluid temperature within the boiling chamber, are strategically located to determine the homogeneity of the temperature distribution prior to the start of a test, and obtain limited temperature profiles during the test. The operating temperature range of the BXF is 35 to $59^{\circ} \mathrm{C}$. The fluid is removed from the bottom of the chamber through exit ports adjacent to the NPBX heater wafer.

A heat exchanger is mounted to the CV base plate. When the CV is mounted within the MSG, this heat exchanger will be positioned directly above the MSG cold plate. While the MSG does provide some cooling via its air recirculation system, the use of the MSG cold plate minimizes the size of the BXF heat exchanger.

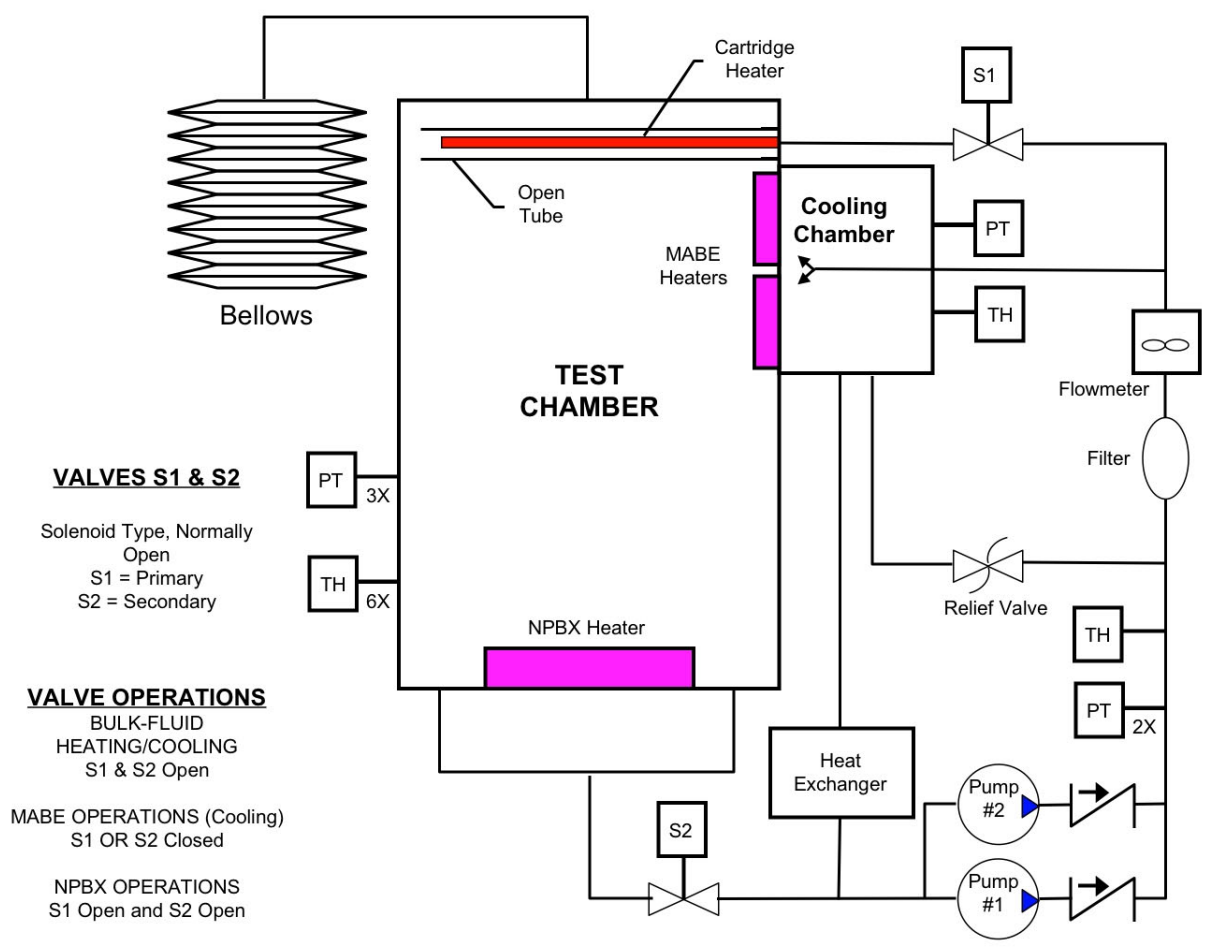

Figure 4.-BXF flow schematic. 
The cooling chamber is discussed in the next section; however, its purpose is to prevent lateral conduction among the microheaters by always forcing them to be in the "ON" state.

System pressure is maintained via a bellows. The bellows is driven by a stepper motor and was sized to accommodate the expected fluid expansion due to the liquid density differences between 20 and $60{ }^{\circ} \mathrm{C}$ and the growth of a bubble that is $7 \mathrm{~cm}$ in diameter. No provisions have been made to adjust the fluid temperature within the bellows to match the temperature within the boiling chamber. Therefore, any fluid displacement into the bellows will likely be of "warm" chamber fluid into "cooler" bellows fluid and any fluid displacement from the bellows into the boiling chamber will likely be of "cool" fluid into the "warmer" boiling chamber. The operating pressure range is 61 to $270 \mathrm{kPa}$.

\section{Cooling chamber}

The primary purpose of the cooling chamber is to satisfy the science requirements for the MABE, namely, ensure that the microheater arrays are always "ON." While the control circuitry is being designed to sense and control temperatures to within $0.35^{\circ} \mathrm{C}$, it is possible that once heaters achieve their set point, the control circuitry may shut off power. Meanwhile, adjacent heaters that have a slightly higher set point temperature, but still within the $0.35{ }^{\circ} \mathrm{C}$ margin, may start to laterally heat the microheaters that were turned off. In order to prevent this scenario, it is necessary to provide a minimum amount of cooling to the backside of the MABE heater array by jetting fluid onto it.

The secondary purpose is to minimize the pressure differential across the MABE quartz substrate, and thus the pressure differential between the cooling chamber and the boiling chamber. The benefit of this approach is that the cooling and boiling chamber structures can then carry the brunt of the pressureinduced loading that the fluid will see during testing for pressure conditions ranging from 61 to $270 \mathrm{kPa}$.

The cooling chamber provides the mounting for both MABE microheater arrays that are mounted into pin grid assemblies (PGAs). A pc board then interfaces between the PGA's and multiple conductor connectors that are welded into the side of the cooling chamber. An earlier version of the cooling chamber is shown in figure 5. As can be seen, there are a substantial number of wires between the connectors and the pc board.

The next version of the chamber will use "flex circuits" to link the connectors on the outer wall to the pc board.

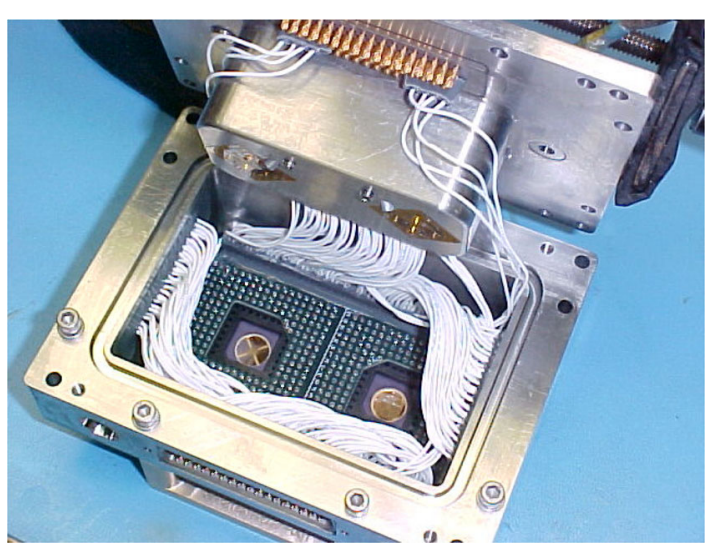

Figure 5.-View of BXF cooling chamber internal wiring and cooling nozzles. 


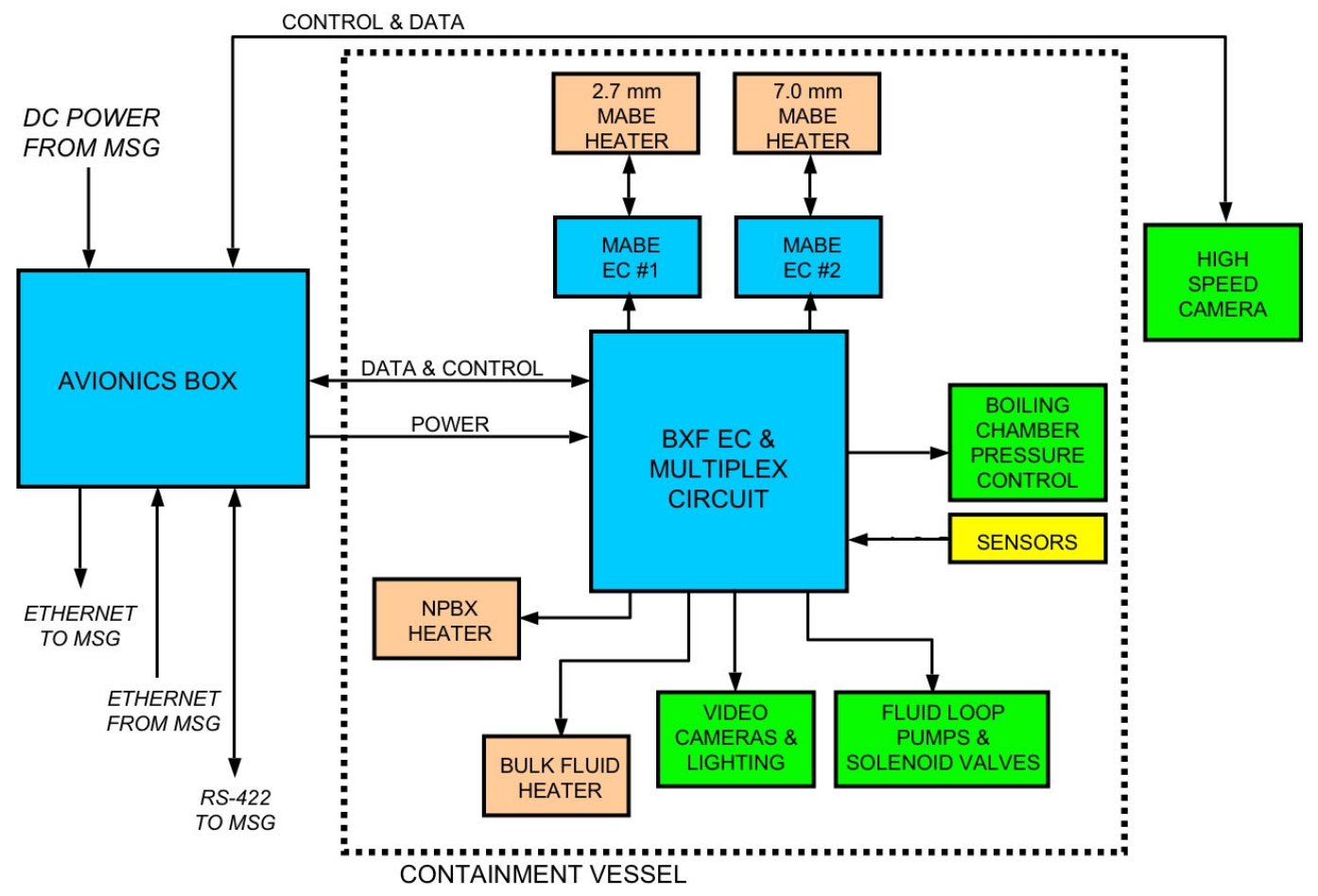

Figure 6.-BXF control system block diagram.

\section{Embedded control circuitry}

In order to minimize the amount of electrical connectors through the $\mathrm{CV}$ wall, especially given that there are 192 microheaters, embedded controller (EC) boards were located in the CV. Power and commands are fed from the $\mathrm{AB}$ to the ECs, which disperse and interpret them as appropriate, and the ECs send data and status back to the AB. This is illustrated in figure 6. There are two MABE EC's with one dedicated to each of the two microheater arrays. The BXF EC is responsible for the remaining controller assignments including the NPBX heater, bulk fluid temperature, pumps, valves, pressure control, thermisters, cameras, lighting, and MABE array selection. The BXF EC also produces a $500 \mathrm{~Hz}$ clocking signal which is used to synchronize the start of a data acquisition cycle from the 96 microheaters and to start the acquisition of a high-speed video camera image.

\section{CV construction}

The CV housing is constructed of a cylinder and two pieces of plate aluminum. The cylinder is made of T6061 aluminum, about $10 \mathrm{~mm}$ thick, with an external diameter of $400 \mathrm{~mm}$. The top and bottom plates are $25 \mathrm{~mm}$ thick and are fabricated from 7075 aluminum. The CV has a total height of $480 \mathrm{~mm}$.

A double gasket arrangement is used to provide triple containment of the fluid for any "credible" leak path. The first level of containment is the experiment itself, including the boiling chamber, bellows, cooling chamber and other associated plumbing. The $\mathrm{CV}$ walls provide an additional level of containment and are not considered to be a credible leak path except for the seals. There are three areas where seals are present: The base plate to $\mathrm{CV}$ wall, the top plate to $\mathrm{CV}$ wall, the electrical connection feed-throughs, and the window for the high speed camera. There is a special sampling space and portal to verify seal integrity between the outer and middle seals as shown in figure 7. 

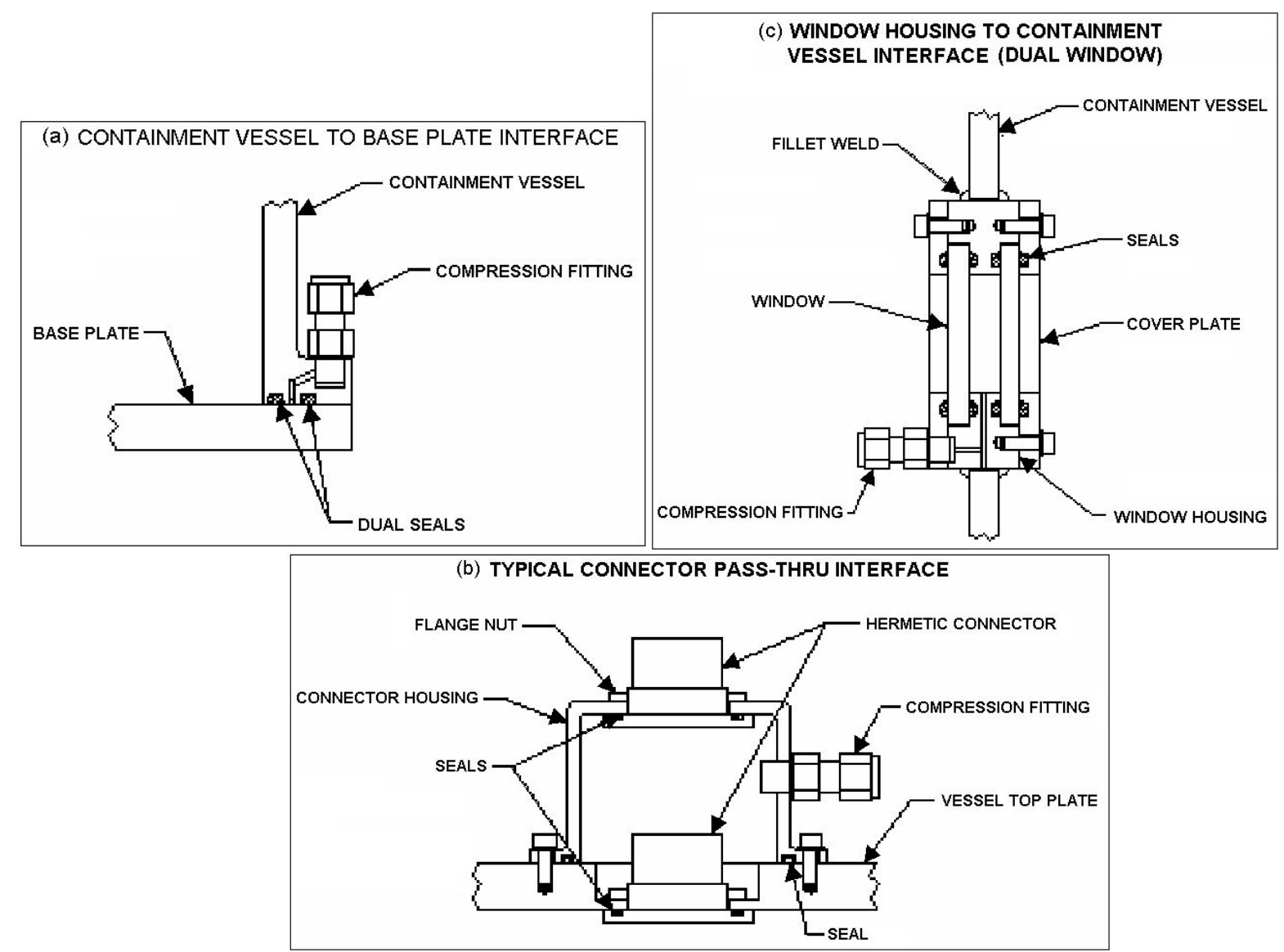

Figure 7.-Seal design methodology: (a) CV walls to base plate, (b) electrical feed-throughs, (c) windows.

The CV also provides a mounting point for the Photron Ultima-512 high speed camera body. The camera is used to visualize through the $\mathrm{CV}$ window and the cooling chamber to view the bottom of the MABE microheater arrays. In order to ensure alignment between the camera and the arrays, it is necessary to use a mirror attached to the outside of the CV. The optics have been selected so that each heater array occupies the majority of the imager's field of view. However, in order to accommodate this ability, it is necessary for the astronaut to relocate the camera from one position on the CV to a second, predetermined, position and replace the microscopic lens with another lens of the appropriate focal length. Images from the camera are sent to the processing unit that is mounted to the top of the AB.

\section{Avionics Box}

The Avionics Box provides multiple interfaces (see figure 6) between the ISS and the CV. These interfaces are for power, data, and commands. Primary components of the $\mathrm{AB}$ include power converters and conditioning, a PC-104 Bus computer, and removable hard drives. The data processing and control unit for the Photron Ultima-512 camera is mounted to the top of the AB.

The $\mathrm{AB}$ receives $120 \mathrm{VDC}$ from ISS through the MSG. This voltage is converted to the following levels:

- $\quad+5$ VDC for use by the PC104 Stack and removable hard drive in the AB.

- $\quad+12 \mathrm{VDC}$ for use by the removable hard drive in the $\mathrm{AB}$ and is routed into the $\mathrm{CV}$ for use by the MABE and BXF embedded controller boards.

- $\quad+24 \mathrm{VDC}$ is routed into the $\mathrm{CV}$ for various loads such as the pumps, valves, instrumentation, and the MABE ECs. 
With the exception of the Photron Ultima-512 camera, a "single point ground" has been incorporated into the design for the BXF. Because this camera is COTS and is internally grounded, it was decided not cost-effective to modify the camera to incorporate a single point ground to the BXF. A payload hazards analysis was completed to verify the safety of this arrangement.

Thermal switches are positioned within the $\mathrm{AB}$ to sense high temperature conditions and shut off power to the $\mathrm{AB}$ and $\mathrm{CV}$ in the event of temperature levels above $70{ }^{\circ} \mathrm{C}$.

The PC-104 Bus is a "stackable" configuration of a Pentium (Intel) processor; i.e., capability can be added to the base process by stacking additional boards on top of the processing board. In terms of communication, the PC-104 bus has the following capabilities. One ethernet connection is used to the MSG Laptop Computer (MLC) for file transfer between MSG and the BXF. While the test matrix will be resident within the PC104 computer, modified command files can be uploaded from the Telescience Support Center (TSC) to the BXF as necessary. Data is downloaded from the BXF to the MLC and is eventually downlinked to the PI's. A second Ethernet connection is used to command between the AB and the Photron Ultima-512 data processing and control unit and to downlink camera data. Three RS232 connections are used to interface with the ISS rack controller (SPLC), the BXF embedded controller, and the two MABE embedded controller boards through the BXF embedded controller. Commanding to the $\mathrm{BXF}$ and MABE embedded controllers and data transfer from them are accomplished via these controllers. Finally, there is an analog/digital converter on the PC-104 and associated sensors for health monitoring within the $\mathrm{AB}$.

Finally, within the $\mathrm{AB}$ is a receptacle for removable hard drives. For MABE alone, there are over 400 tests each acquiring data from up to 96 microheaters for $25 \mathrm{sec}$ at $500 \mathrm{~Hz}$. However, this amount of data is insignificant considering that the high speed camera has a 512 by 512 pixel array acquiring data for $4 \mathrm{sec}$ also at $500 \mathrm{~Hz}$. Consequently, the data storage is approximately 200 gigabytes (GB). Two $128 \mathrm{~GB}$ hard drives will be required and two additional drives will be stowed as back-ups.

\section{BXF Science Heaters}

As was mentioned earlier, the BXF accommodates two science investigations, MABE and NPBX, and each investigation has its own custom-designed heaters. Initial versions of these heaters were conceptualized, designed, built and tested by each principal investigator and his team. Testing included both normal gravity testing and reduced gravity testing aboard the NASA KC-135 aircraft. Each heater is designed to fulfill the science objectives of that particular investigation.

\section{MABE Heaters}

The objective of this study is to determine the boiling heat transfer mechanisms in microgravity and correlate local heat transfer coefficients versus the vapor and liquid positions for nucleate and transition boiling regimes and at critical heat flux conditions. While most boiling studies have focused on providing a constant power or heat flux at the heater surface, MABE uses a constant temperature approach for controlling heater power.

There are several advantages for using this approach:

- The risk of heater burnout is minimized, especially at critical heat flux and heater dryout conditions. As vapor engulfs the heater surface, less power is required to maintain the heater temperature. As cold liquid contacts the heater surface, more power is required. Burnout occurs when the heater surface is dry and its temperature becomes elevated.

- Lateral substrate conduction is minimized. Since adjacent microheaters are maintained at or nearly at the same temperature, there is very little thermal conduction among microheaters. Only the outer rows of active microheaters conduct significant amounts of heat laterally outward on the quartz substrate. These microheaters actually serve as "guard heaters." 
The development of the microheater arrays involved both arrays themselves, their control circuitry and their calibration technique.

\section{Microheater arrays}

As such, these local surface heat flux and temperature measurements are provided by an array of ninety-six platinum resistance heaters deposited on a quartz wafer. Two of these arrays are used in the BXF: An array of 2.7 by $2.7 \mathrm{~mm}$ and an array of 7.0 by $7.0 \mathrm{~mm}$. An image of the $2.7 \mathrm{~mm}$ array is shown in figure 8 . For the $2.7 \mathrm{~mm}$ array, each of the individual heaters is about 0.26 by $0.26 \mathrm{~mm}$ in size, has a nominal resistance of $975 \Omega$ and a nominal temperature coefficient of resistance of $2 \Omega /{ }^{\circ} \mathrm{C}$. For the $7.0 \mathrm{~mm}$ array, individual heaters are about 0.70 by $0.70 \mathrm{~mm}$ in size, has a nominal resistance of $250 \Omega$ and a nominal temperature coefficient of resistance of $6 \Omega /{ }^{\circ} \mathrm{C}$. Platinum is sputtered onto the entire surface of a $500 \mu \mathrm{m}$ thick wafer to a thickness of $0.2 \mu \mathrm{m}$, a layer of photoresist is deposited and patterned to define the heater geometry, then the platinum from the un-masked areas is removed using an ion mill to form a resistance heater. Aluminum is then vapor deposited to a thickness of $1 \mu \mathrm{m}$ onto the surface, the aluminum power leads are masked off, and the remaining aluminum is removed using a wet chemical etch. A layer of $\mathrm{SiO}_{2}$ is finally deposited over the heater array to provide the surface with a uniform surface energy. The boiling surface was viewed under an electron microscope, and the surface roughness was found to be on the order of the thickness of the aluminum power leads to the heaters $(\sim 1 \mu \mathrm{m})$.

The completed quartz wafer is diced into chips, each containing a single heater array. The chips are mounted on a pin-grid-array (PGA) package using epoxy adhesive, and the pads on the PGA are connected to the power leads of the heater array chip using a conventional wirebonding technique. The completed package is then mounted in a PGA socket that is ultimately mounted in the cooling chamber. Electrical connections are then made to the MABE embedded controller boards.

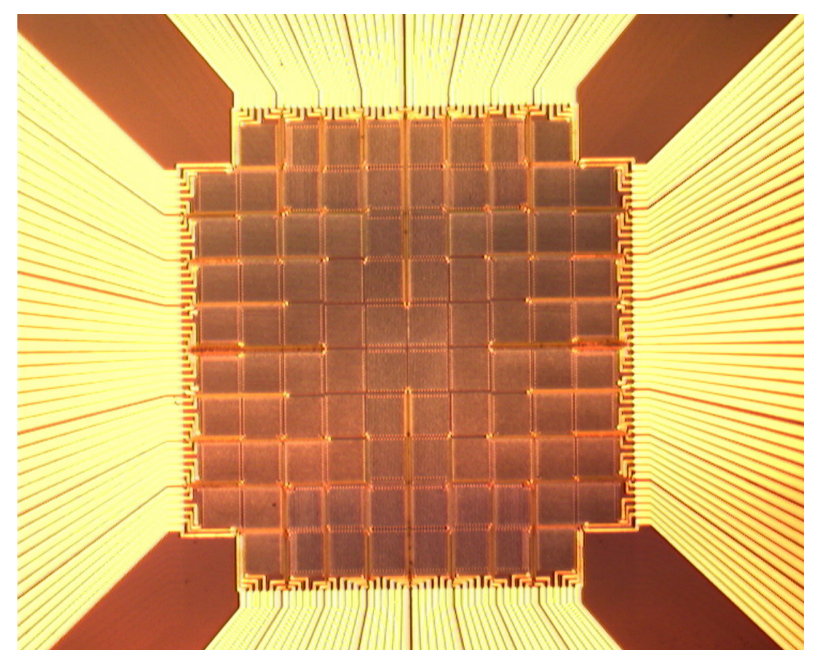

Figure 8.-Microscopic image of 2.7 by $2.7 \mathrm{~mm}$ microheater array. 
Since several of these microheater arrays are manufactured at any give time, the selection process for the flight arrays is based primarily on the resistance measurements made at room temperature and recorded from pin to pin across all 96 microheaters. The microheater arrays that were selected for space flight typically had the most "functional" microheaters and the smallest standard deviation of resistance for those functional heaters. The occurrence of nonfunctional microheaters occurred because of either poor quality control during the deposition onto the quartz substrate or from damage to the wirebonding between the array and the PGA. Both "shorts" and "opens" occurred. Table 1 shows the characteristics of the microheater arrays selected for the space flight experiment.

TABLE 1.-MICROHEATER ARRAYS SELECTED FOR FLIGHT

\begin{tabular}{|l|c|c|}
\hline Heater array size $(\mathrm{mm})$ & 2.7 & 7 \\
\hline Serial no. & $10 \mathrm{~A}$ & 7 \\
\hline Minimum resistance $(\Omega)$ & 918 & 217.1 \\
\hline Average resistance $(\Omega)$ & 973 & 268.0 \\
\hline Maximum resistance $(\Omega)$ & 1008 & 299.8 \\
\hline Standard deviation $(\Omega)$ & 20 & 20 \\
\hline No. of "open" microheaters & 0 & 0 \\
\hline No. of "shorted" microheaters & 0 & 2 \\
\hline No. of "good" microheaters & 96 & 94 \\
\hline
\end{tabular}

\section{Control circuit}

The temperature of each heater in the array is kept constant by feedback circuits using a Wheatstone Bridge and is similar to the technique used in constant temperature hot-wire anemometry. It was strongly desired though, to design an optimized circuit that could provide the necessary temperature sensitivity over the range of operation $\left(50\right.$ to $\left.110^{\circ} \mathrm{C}\right)$ as well as provide a "continuity" check at room temperature using the circuit for all 96 microheaters. Thus, one needs to account for the variation in resistances among the microheaters and for resistance as a function of temperature.

A concept for the modeling the circuit is show in figure 9. For this concept, the microheater resistance can be approximated as follows:

$$
R_{H}=R_{\text {HBase }}+R_{H A d j}
$$

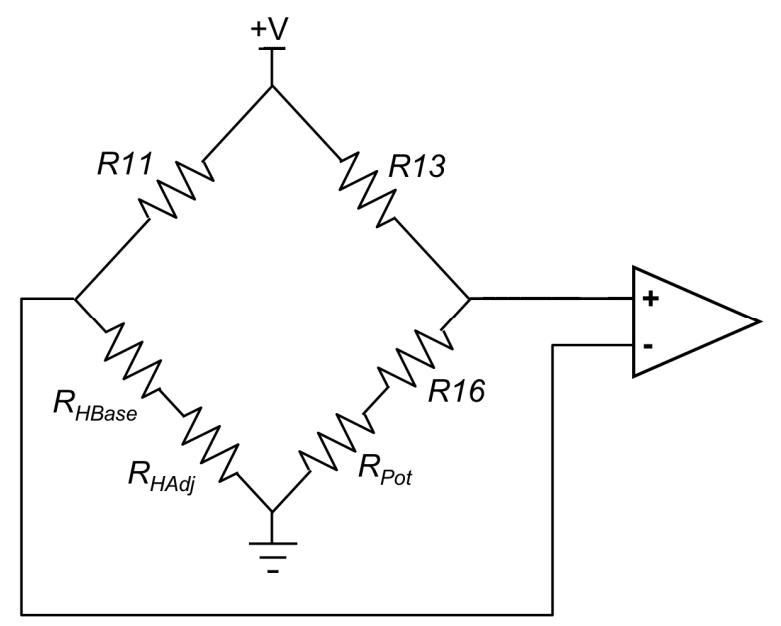

Figure 9.-Basic microheater control circuit concept. 
Where

$R_{H} \quad$ is the microheater resistance in ohms,

$R_{\text {HBase }}$ is the "base" or minimum expected resistance (in ohms) among all of the microheaters,

$R_{H B A d j}$ is the difference between the minimum and maximum microheater resistance at room temperature and the average change anticipated for the microheater resistance also in ohms.

In order to balance the bridge,

$$
\frac{R 11}{R_{H}}=\frac{R 13}{R 16+R_{\text {Pot }}}
$$

Where $R 11, R 13$, and $R 16$ are fixed resistor values in ohms; and $R_{P o t}$ is the resistance value of the digital potentiometer.

The desired operating temperature is obtained by driving a digital potentiometer $R_{P o t}$ in one leg of the bridge. The instantaneous power is obtained by measuring the current to balance the bridge and is then used to obtain the spatially and temporally resolved heat transfer coefficients and boiling curves.

Besides the range of microheater resistance at room and elevated, temperatures, other parameters need to be considered:

- Providing sufficient power to be dissipated by the microheater,

- Minimizing power consumption and thermal dissipation on the embedded controller board, namely in $R 11, R 13, R 16$, and $R_{P o t}$, to avoid thermal management issues,

- Matching the upper bridge resistance, $R 11$, with the lower bridge resistance, $R_{H}$, to provide maximum bridge sensitivity,

- Providing sufficient current on the right hand side of the bridge to avoid noise,

- Ensuring that digital potentiometer has sufficient discrete step resolution to achieve the necessary temperature resolution, and

- Availability of parts.

The algorithm that was utilized involves first selecting a digital potentiometer with an appropriate number of discrete steps. Next, a ratio is calculated between the resistance ratio of $R_{P o t}$ and $R_{H A d j}$. This same ratio is then used to find $R 16$ based on $R_{\text {HBase }}$ and $R 13$ based on $R 11$. Details of the specific resistor values are not within this report as that process is still ongoing.

\section{NPBX Heater}

This heater was designed to study bubble nucleation, growth and departure, and the cooling that is achieved under microgravity conditions by controlling the location of the bubble nucleation. Through specification of the wall superheat and the bulk liquid subcooling, it is possible to control the rate of bubble growth. This data will be used to verify models being developed by the investigator and his research team.

During the initial stages of the investigation, the heater was a $100 \mathrm{~mm}$ polished silicon wafer. The wafer was $400 \mu \mathrm{m}$ thick. Boiling cavities were sized based on the relationship between the wall superheat and cavity size proposed by Wang and Dhir (ref. 12).

$$
\Delta T=\frac{4 \sigma T_{S a t}}{\rho_{V} h_{f g} D_{c}} K_{M a x}
$$


Where

$$
\begin{array}{lll}
K_{\max }=1 & \text { for } & \phi \leq 90^{\circ} \\
K_{\text {Max }}=\sin \phi & \text { for } & \phi>90^{\circ}
\end{array}
$$

Five cavities were created by placing a mask over the wafer and using a chemical etchant to create cylindrical openings with a $10 \mu \mathrm{m}$ opening and approximately a $10 \mu \mathrm{m}$ depth. Nucleation sites are show relative to each other in figure 10 . The silicon wafer had a surface that was exceptionally smooth so it very easy to limit the number of nucleation sites to only the manufactured sites. Unfortunately though, silicon is also relatively brittle. Given this property and the wafer thinness, the wafer could not withstand the range of differential fluid pressures to which it was exposed during the MABE test matrix without cracking. Aluminum was selected as the new wafer material.

Aluminum has a similar thermal conductivity as silicon but has much better ductility. However, aluminum is also relatively soft and the polishing process can result in surface pitting at the microscopic level. A polished wafer is shown in figure 11.

An attempt to deposit a silicon dioxide layer on the aluminum and use the chemical etchant process to generate cavities was attempted. A typical result is shown in figure 12. The "dark" areas surrounding the cavity are from the pitting that occurred during polishing. This etchant process was discarded as the technique of choice given that while the cavity opening at the surface (the dark central circle) was within specifications, no information could be gleaned concerning the depth of the cavity or the shape.

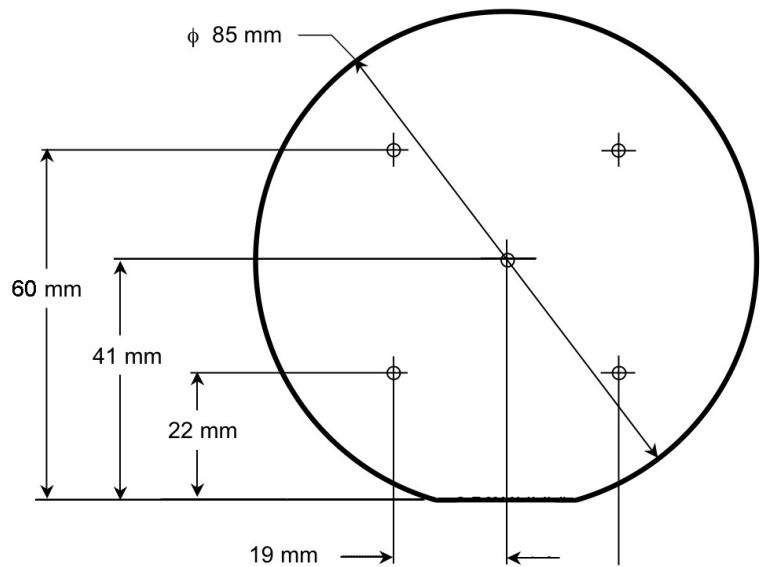

Figure 10.-Cavity location on NPBX wafer heater.

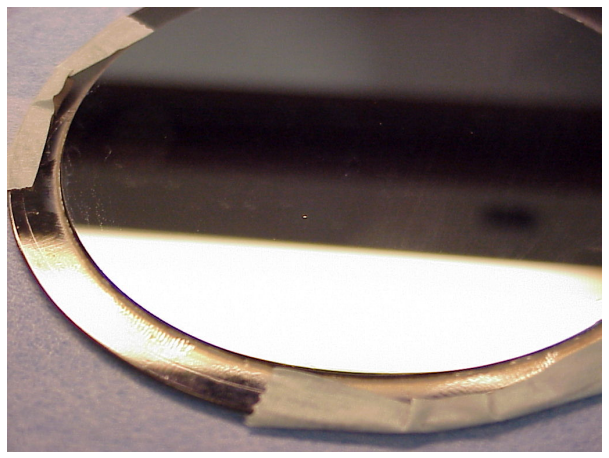

Figure 11.-Polished aluminum wafer for use as NPBX heater.

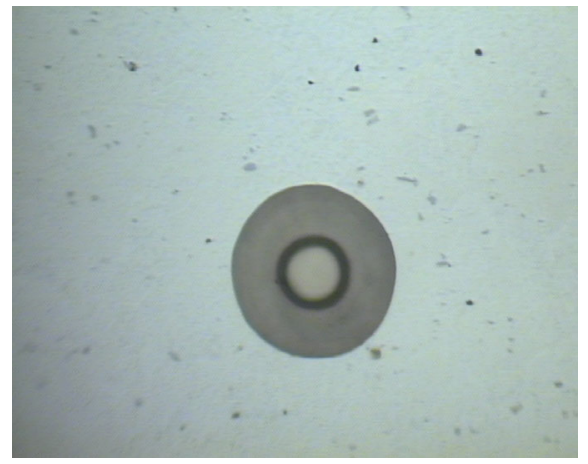

Figure 12.-Chemical etched cavity in aluminum wafer. 


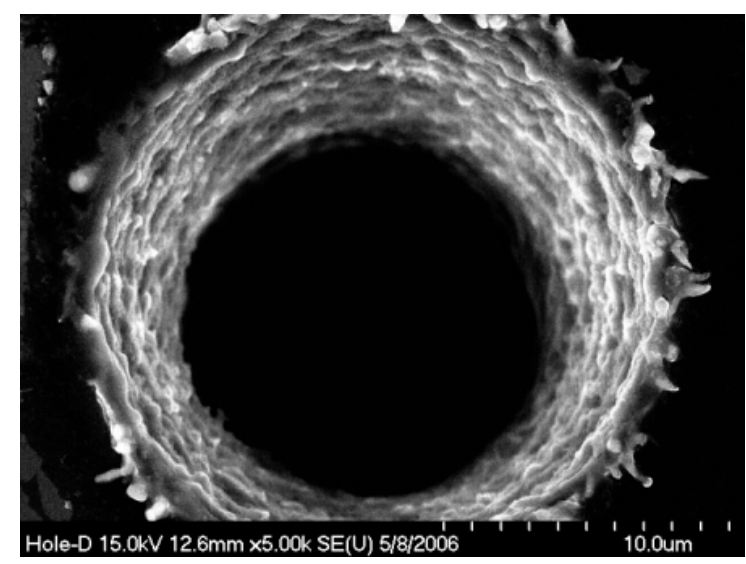

Figure 14.-Cavity created along edge of wafer using EDM.

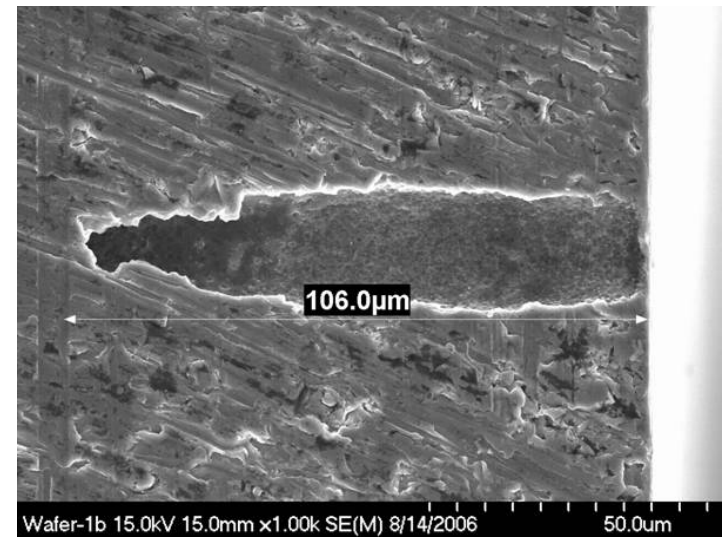

Figure 13.-Cavity created using EDM.

Instead, an electrical discharge machining (EDM) technique was used. Scanning electron microscope images of cavities from the wafer surface and of "test" cavities machined along the edge of wafer are shown in figures 13 and 14 respectively. These images show that significant control can be exerted during the wafer fabrication process, thus EDM will be used to generate the cavities that are $20 \mu \mathrm{m}$ in diameter and approximately $100 \mu \mathrm{m}$ in depth. The flight experiment wafer will be $85 \mathrm{~mm}$ in diameter and have a "flat" to assist with positioning the wafer for machining the cavities and alignment with the BXF for imaging purposes.

The wafer is instrumented on its "backside," with heaters and thermisters, i.e., the wafer side without the cavities. The heaters are strain gages that are grouped so that the wafer can be heated in zones. The zones are divided among each of the cavities with each cavity having a "cavity heater" and a group of "surround heaters." A thermister in each zone is used to provide feedback for the control circuitry. The basic control circuit is similar to that used by the MABE embedded controllers. Bubble nucleation is controlled by software using the following logic:

- For the selected heater cavity, the surround and cavity heaters are set to the wall superheat temperature specified in the test matrix.

- The cavity heater is then ramped up in temperature at a rate whereby the heat flux does not exceed 2 watts $/ \mathrm{cm}^{2}$.

- Upon nucleation, the vaporization will cause a sudden temperature drop that will be detected by the thermister and will trigger the software to set the cavity temperature to the wall superheat temperature specified in the test matrix. This is achieved by reducing the power to the heater.

This process is expected to last less than $30 \mathrm{sec}$, with the nucleation and power reduction to occur within $1 \mathrm{sec}$.

\section{Test Matrices}

There will be significant normal gravity testing to check out operations of the BXF and obtain baseline normal gravity testing. Both the MABE and the NPBX test matrix are included and discussed within this section. 


\section{MABE Test Matrix}

Table 2 presents the 18 test conditions that specify the microheater array size, the bulk liquid temperature, and the system pressure. Each condition has several heater temperatures and specifies the heater array size of 96,64 , and 36 microheaters. The 96 microheater configuration is 10 by 10 array (minus the four corner), the 64 microheater configuration corresponds to 8 by 8 array and the 36 microheater configuration corresponds to a 6 by 6 array. For the 96 microheater configuration tests, a range of heater temperatures is specified in $5^{\circ}$ increments.

TABLE 2.-MABE TEST MATRIX

\begin{tabular}{|c|c|c|c|c|c|}
\hline $\begin{array}{c}\text { Test } \\
\text { conditions no. }\end{array}$ & $\begin{array}{c}\text { Heater array } \\
\text { size, } \\
(\mathrm{mm})\end{array}$ & $\begin{array}{c}\text { Bulk liquid } \\
\text { temperature, } \\
\left({ }^{\circ} \mathrm{C}\right)\end{array}$ & $\begin{array}{c}\text { Pressure } \\
(\mathrm{kPa}), \\
\mathrm{T}_{\text {sat }}\left({ }^{\circ} \mathrm{C}\right)\end{array}$ & $\begin{array}{c}\text { Number of } \\
\text { active } \\
\text { heaters }\end{array}$ & $\begin{array}{l}\text { Heater temperatures, } \\
\qquad\left({ }^{\circ} \mathrm{C}\right)\end{array}$ \\
\hline 1 & 2.7 & 40 & 61,42 & $96,64,36$ & $\begin{array}{l}95,90,85,80,75,70,65 \\
60,55,50\end{array}$ \\
\hline 2 & 2.7 & 55 & 101,56 & $96,64,36$ & $\begin{array}{l}110,105,100,95,90,85 \\
80,75,70,65\end{array}$ \\
\hline 3 & 2.7 & 60 & 202,79 & $96,64,36$ & $110,105,100,95,90,85$ \\
\hline 4 & 2.7 & 35 & 61,42 & $96,64,36$ & $\begin{array}{l}95,90,85,80,75,70,65 \\
60,55,50\end{array}$ \\
\hline 5 & 2.7 & 45 & 101,56 & $96,64,36$ & $\begin{array}{l}1110,105,100,95,90,85, \\
80,75,70,65\end{array}$ \\
\hline 6 & 2.7 & 50 & 202,79 & $96,64,36$ & $110,105,100,95,90,85$ \\
\hline 7 & 2.7 & 30 & 61,42 & $96,64,36$ & $\begin{array}{l}95,90,85,80,75,70,65 \\
60,55,50\end{array}$ \\
\hline 8 & 2.7 & 35 & 101,56 & $96,64,36$ & $\begin{array}{l}110,105,100,95,90,85, \\
80,75,70,65\end{array}$ \\
\hline 9 & 2.7 & 35 & 202,79 & $96,64,36$ & $110,105,100,95,90,85$ \\
\hline 10 & 7 & 40 & 61,42 & $96,64,36$ & $\begin{array}{l}95,90,85,80,75,70,65 \\
60,55,50\end{array}$ \\
\hline 11 & 7 & 55 & 101,56 & $96,64,36$ & $\begin{array}{l}110,105,100,95,90,85, \\
80,75,70,65\end{array}$ \\
\hline 12 & 7 & 60 & 202,79 & $96,64,36$ & $110,105,100,95,90,85$ \\
\hline 13 & 7 & 35 & 61,42 & $96,64,36$ & $\begin{array}{l}95,90,85,80,75,70,65 \\
60,55,50\end{array}$ \\
\hline 14 & 7 & 45 & 101,56 & $96,64,36$ & $\begin{array}{l}110,105,100,95,90,85 \\
80,75,70,65\end{array}$ \\
\hline 15 & 7 & 50 & 202,79 & $96,64,36$ & $110,105,100,95,90,85$ \\
\hline 16 & 7 & 30 & 61,42 & $96,64,36$ & $\begin{array}{l}95,90,85,80,75,70,65 \\
60,55,50\end{array}$ \\
\hline 17 & 7 & 35 & 101,56 & $96,64,36$ & $\begin{array}{l}110,105,100,95,90,85 \\
80,75,70,65\end{array}$ \\
\hline 18 & 7 & 35 & 202,79 & $96,64,36$ & $110,105,100,95,90,85$ \\
\hline
\end{tabular}

Critical Heat Flux (CHF) will be reached for a majority of the test conditions, generating a wealth of data regarding the influence liquid subcooling, pressure, and heater size on boiling. This test protocol will generate boiling curves from the transition boiling regime through $\mathrm{CHF}$ and into nucleate boiling. Forty sec of data will be obtained at each temperature after the heaters have been set to the desired wall temperature. The duration of data acquisition time depends on the how fast the boiling process reaches equilibrium. 
For the 64 and 36 microheater configuration tests, the range of heater temperatures is specified in $10^{\circ}$ increments. This will enable the effect of heater size on boiling to be studied.

Side and bottom view video images will be obtained. Fewer runs will be made at the higher pressures since the saturation temperature of the fluid increases with pressure.

Four images from the high speed video camera, pressure, liquid and microheater temperatures will be downlinked whenever possible to enable the investigator to adjust the test matrix as appropriate. Synchronization of the heat transfer, video, acceleration, and video data is required.

\section{NPBX Test Matrix}

The focus of these flight experiments is to study bubble inception, bubble growth, bubble departure and bubble merger. Liquid subcooling and wall superheat and, indirectly, wall heat flux will be varied parametrically. Table 3 presents list the test matrix of 48 experiments. These experiments are conducted at three different system pressures at the same initial bulk liquid temperature. Thus, three subcooling levels will be studied at four different wall superheats. For the first two wall superheats, only a single cavity will be nucleated. For $12{ }^{\circ} \mathrm{C}$ wall superheat, three cavities will be nucleated, whereas for $14{ }^{\circ} \mathrm{C}$, five cavities are nucleated.

TABLE 3.-NPBX TEST MATRIX

\begin{tabular}{|c|c|c|c|c|c|c|c|c|}
\hline \multirow{2}{*}{$\begin{array}{c}\text { Bulk liquid } \\
\text { temperature, } \\
\left({ }^{\circ} \mathrm{C}\right)\end{array}$} & \multirow[t]{2}{*}{$\begin{array}{c}\text { Pressure, } \\
(\mathrm{kPa})\end{array}$} & \multirow[t]{2}{*}{$\begin{array}{c}\text { Subcooling, } \\
\left({ }^{\circ} \mathrm{C}\right)\end{array}$} & \multicolumn{4}{|c|}{$\begin{array}{l}\text { Wall superheat, } \\
\left({ }^{\circ} \mathrm{C}\right)\end{array}$} & \multirow{2}{*}{$\begin{array}{l}\text { Test duration }^{1} \text { for } \\
\text { each superheat, } \\
\text { (minutes) }\end{array}$} & \multirow[t]{2}{*}{$\begin{array}{l}\text { Maximum } \\
\text { heat flux }\end{array}$} \\
\hline & & & 8 & 10 & 12 & 14 & & \\
\hline 59 & 150 & $\sim 10$ & 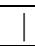 & I & 1 & I & 6 & \multirow[t]{4}{*}{$2 \mathrm{~W} / \mathrm{cm}^{2}$} \\
\hline 59 & 130 & $\sim 5$ & | & I & I & I & 6 & \\
\hline 59 & 110 & $\sim 0$ & I & I & 1 & 1 & 6 & \\
\hline 59 & 130 & $\sim 5$ & $\downarrow$ & $\downarrow$ & $\downarrow$ & $\downarrow$ & 6 & \\
\hline
\end{tabular}

The test sequence is performed so that tests with the highest pressure (highest subcooling) are performed first. With the system maintained at a fixed pressure, the power input to the heaters is increased in steps. The first test in each series will be conducted at the lowest wall superheat. The fourth test is for repetition. The temperature steps and the cavity diameter are chosen so that one, three, and five cavities nucleate at the two lowest, middle and highest temperatures, respectively. The two lowest superheats will provide data on single bubbles and bubble merger on the axis perpendicular to the heater surface. Data for bubble merger in the lateral direction will be obtained at the two highest superheats.

The heat loss from the test chamber and through the cooler and pressure relief from the bellows will provide the necessary control to achieve and maintain the desired liquid temperature and system pressure before the start of each test, during performance of each test, or after completion of the preceding test.

\section{Current Status and Plans}

Currently, the BXF Project is designing the MABE embedded controller boards. Fabrication will be followed by calibration of the MABE EC's with the MABE microheater arrays and additional testing. An engineering prototype of the NPBX heater wafer is being tested to develop the software necessary to for boiling nucleation. After both of these developmental tasks are completed, these heaters will be integrated into the space flight hardware and undergo additional testing.

The ISS resource requirements currently contemplated are as follows

- Upmass-98.2 kg

- Volume- $0.144 \mathrm{~m}^{3}$

- Power consumption (including MSG systems) - $785 \mathrm{~W}$ 
- Crew time- $8 \mathrm{hr}$ for installation and operations

- Autonomous operations time (worst case) $-600 \mathrm{hr}$.

- 8 video tapes

- 4 hard drives (120 GB each)

The BXF is currently planned for launch on the Shuttle to the ISS in late-2009. BXF will be operated during ISS increments 20 and/or 21. As such, flight hardware availability is planned for August 2009 and crew training is tentatively planned for mid-2009.

\section{References}

1. Zhang H., Mudawar I., Hasan M.M., "Flow boiling CHF in microgravity," International Journal of Heat and Mass Transfer, vol. 48, pp. 3107-3118, 2005.

2. Siegel, R., and Keshock, E.G., "Effects of Reduced Gravity on Nucleate Boiling Bubble Dynamics in Saturated Water," A.I.Ch.E. Journal, vol. 10, pp. 509-517, 1964.

3. Merte, H. Jr., Lee, H.S., and Keller, R.B., "Report on Pool Boiling Experiment Flown on STS-47 (PBE-IA), STS-57 (PBE-IB), and STS-60 (PBE-IC),” NASA CR-198465, 1996.

4. Di Marco, "Review of Reduced Gravity Boiling Heat Transfer: European Research," J. Japanese Society of Microgravity Applications, 20, 252-263, 2003.

5. J. Kim, "Review of Reduced Gravity Boiling Heat Transfer: US Research," J. Japanese Society of Microgravity Applications, 20, 264-271, 2003.

6. H. Ohta, "Review of Reduced Gravity Boiling Heat Transfer: Japanese Research," J. Japanese Society of Microgravity Applications, vol. 20, pp. 272-285, 2003.

7. Wu, Jinfeng, Dhir, Vijay K., and Qian, Jianliang, "Numerical Simulation of Subcooled Nucleate Boiling by Coupling Level-Set Method with Moving-Mesh Method," Numerical Heat Transfer, Part B: Fundamentals, 51:6, 535-563, 2007.

8. Raj, R. and Kim, J., "Thermocapillary Convection During Subcooled Boiling In Reduced Gravity Environments," Proceedings of ITP2007: Interdisciplinary Transport Phenomena V: Fluid, Thermal, Biological, Materials and Space Sciences, Bansko, Bulgaria, 2007.

9. Tortelli, V., Tonelli, C., "Thermal decomposition of branched-chain perfluoroalkanes," Journal of Fluorine Chemistry, vol. 60, pp. 165-174, 1993.

10. Arnold, W.A., Hartman, T.G., and McQuillen, J. "Chemical Characterization and Thermal Stressing Studies of Perfluorohexane Fluids for Space-Based Applications," Journal of Spacecraft and Rockets, pp. 94-101, vol. 44, 2007.

11. Henry, C.D., Kim, J., Chamberlain, B., and Hartman, T.G., "Heater Size And Heater Aspect Ratio Effects on Subcooled Pool Boiling Heat Transfer in Low-G," 3rd International Symposium on TwoPhase Flow Modeling and Experimentation, Pisa, 2004.

12. Wang C.H., Dhir V.K., "On the Gas Entrapment and Nucleation Site Density During Pool Boiling of Saturated Water," J Heat Transfer, vol. 115, pp. 670-79, 1993. 


\begin{tabular}{|c|c|c|}
\hline \multicolumn{2}{|c|}{ REPORT DOCUMENTATION PAGE } & $\begin{array}{c}\text { Form Approved } \\
\text { OMB No. 0704-0188 }\end{array}$ \\
\hline \multicolumn{3}{|c|}{$\begin{array}{l}\text { The public reporting burden for this collection of information is estimated to average } 1 \text { hour per response, including the time for reviewing instructions, searching existing data sources, gathering and maintaining the } \\
\text { data needed, and completing and reviewing the collection of information. Send comments regarding this burden estimate or any other aspect of this collection of information, including suggestions for reducing this } \\
\text { burden, to Department of Defense, Washington Headquarters Services, Directorate for Information Operations and Reports (0704-0188), } 1215 \text { Jefferson Davis Highway, Suite } 1204 \text {, Arlington, VA } 222022-4302 \text {. } \\
\text { Respondents should be aware that notwithstanding any other provision of law, no person shall be subject to any penalty for failing to comply with a collection of information if it does not display a currently valid OMB } \\
\text { control number. } \\
\text { PLEASE DO NOT RETURN YOUR FORM TO THE ABOVE ADDRESS. }\end{array}$} \\
\hline $\begin{array}{l}\text { 1. REPORT DATE (DD-MM-YYYY) } \\
01-04-2008\end{array}$ & $\begin{array}{l}\text { 2. REPORT TYPE } \\
\text { Technical Memorandum }\end{array}$ & 3. DATES COVERED (From - To) \\
\hline \multirow{3}{*}{\multicolumn{2}{|c|}{$\begin{array}{l}\text { 4. TITLE AND SUBTITLE } \\
\text { Boiling Experiment Facility for Heat Transfer Studies in Microgravity }\end{array}$}} & 5a. CONTRACT NUMBER \\
\hline & & 5b. GRANT NUMBER \\
\hline & & 5c. PROGRAM ELEMENT NUMBER \\
\hline \multirow{3}{*}{\multicolumn{2}{|c|}{$\begin{array}{l}\text { 6. AUTHOR(S) } \\
\text { DeLombard, Richard; McQuillen, John; Chao, David }\end{array}$}} & 5d. PROJECT NUMBER \\
\hline & & 5e. TASK NUMBER \\
\hline & & $\begin{array}{l}\text { 5f. WORK UNIT NUMBER } \\
\text { WBS } 825080.04 .02 .20 .07\end{array}$ \\
\hline \multicolumn{2}{|c|}{$\begin{array}{l}\text { 7. PERFORMING ORGANIZATION NAME(S) AND ADDRESS(ES) } \\
\text { National Aeronautics and Space Administration } \\
\text { John H. Glenn Research Center at Lewis Field } \\
\text { Cleveland, Ohio 44135-3191 }\end{array}$} & $\begin{array}{l}\text { 8. PERFORMING ORGANIZATION } \\
\text { REPORT NUMBER } \\
\text { E-16311 }\end{array}$ \\
\hline \multirow{2}{*}{\multicolumn{2}{|c|}{$\begin{array}{l}\text { 9. SPONSORING/MONITORING AGENCY NAME(S) AND ADDRESS(ES) } \\
\text { National Aeronautics and Space Administration } \\
\text { Washington, DC 20546-0001 }\end{array}$}} & $\begin{array}{l}\text { 10. SPONSORING/MONITORS } \\
\text { ACRONYM(S) } \\
\text { NASA }\end{array}$ \\
\hline & & $\begin{array}{l}\text { 11. SPONSORING/MONITORING } \\
\text { REPORT NUMBER } \\
\text { NASA/TM-2008-215148; AIAA-2008- } \\
0814\end{array}$ \\
\hline \multicolumn{3}{|c|}{$\begin{array}{l}\text { 12. DISTRIBUTION/AVAILABILITY STATEMENT } \\
\text { Unclassified-Unlimited } \\
\text { Subject Category: } 34 \\
\text { Available electronically at http://gltrs.grc.nasa.gov } \\
\text { This publication is available from the NASA Center for AeroSpace Information, 301-621-0390 }\end{array}$} \\
\hline
\end{tabular}

\section{SUPPLEMENTARY NOTES}

\section{ABSTRACT}

Pool boiling in microgravity is an area of both scientific and practical interest. By conducting tests in microgravity, it is possible to assess the effect of buoyancy on the overall boiling process and assess the relative magnitude of effects with regards to other "forces" and phenomena such as Marangoni forces, liquid momentum forces, and microlayer evaporation. The Boiling eXperiment Facility is now being built for the Microgravity Science Glovebox that will use normal perfluorohexane as a test fluid to extend the range of test conditions to include longer test durations and less liquid subcooling. Two experiments, the Microheater Array Boiling Experiment and the Nucleate Pool Boiling eXperiment will use the Boiling eXperiment Facility. The objectives of these studies are to determine the differences in local boiling heat transfer mechanisms in microgravity and normal gravity from nucleate boiling, through critical heat flux and into the transition boiling regime and to examine the bubble nucleation, growth, departure and coalescence processes. Custom-designed heaters will be utilized to achieve these objectives.

\section{SUBJECT TERMS}

Fluid dynamics; Microgravity; Multiphase flow; International Space Station; Boiling; Heat transfer

\begin{tabular}{|c|c|c|c|c|c|}
\hline \multicolumn{3}{|c|}{ 16. SECURITY CLASSIFICATION OF: } & \multirow{2}{*}{$\begin{array}{l}\text { 17. LIMITATION OF } \\
\text { ABSTRACT } \\
\text { UU }\end{array}$} & \multirow{2}{*}{$\begin{array}{l}\text { 18. NUMBER } \\
\text { OF } \\
\text { PAGES } \\
23\end{array}$} & \multirow{2}{*}{$\begin{array}{l}\text { 19a. NAME OF RESPONSIBLE PERSON } \\
\text { STI Help Desk (email:help@sti.nasa.gov) } \\
\text { 19b. TELEPHONE NUMBER (include area code) } \\
\text { 301-621-0390 }\end{array}$} \\
\hline $\begin{array}{l}\text { a. REPORT } \\
U\end{array}$ & $\begin{array}{l}\text { b. ABSTRACT } \\
U\end{array}$ & $\begin{array}{l}\text { c. THIS } \\
\text { PAGE } \\
\text { U }\end{array}$ & & & \\
\hline
\end{tabular}



